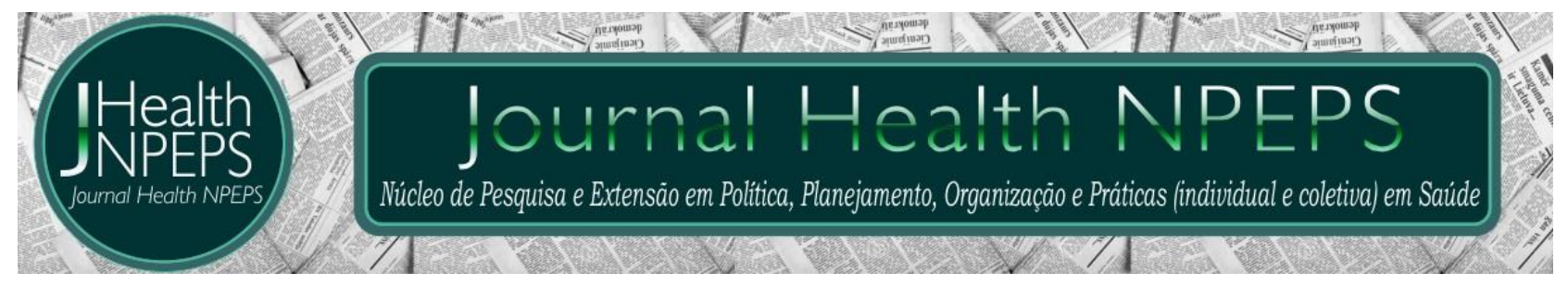

http://dx.doi.org/10.30681/252610103115

ARTIGO ORIGINAL

\title{
Gravidez na adolescência: um desafio crítico para os países do cone sul
}

\author{
Adolescent pregnancy: a critical challenge for the southern cone countries
}

Gravidez en la adolescencia: un desafío crítico para los países del cono sur

\author{
Pâmela Roberta de Oliveira ${ }^{1}$, Juliana Zenaro Rodrigues², Jéssica Dias Ferreira ${ }^{3}$, \\ Daianna Jéssica Rocha Batista ${ }^{4}$, Rodrigo Moraes de Gusmão ${ }^{5}$, Suzicléia Elizabete de \\ Jesus Franco ${ }^{6}$, Elias Marcelino da Rocha ${ }^{7}$, Alisséia Guimarães Lemes ${ }^{8}$
}

\section{RESUMO}

Objetivo: conhecer a experiência de ser mãe na adolescência, bem como, identificar as inferências socioculturais e emocionais que ${ }^{1}$ permearam esta fase. Método: estudo descritivo e exploratório de abordagem qualitativa, desenvolvido a partir do referencial de Bardin. A coleta de dados ocorreu entre janeiro e novembro de 2013, com dez adolescentes residentes em Barra do Garças-MT, a partir de uma entrevista

\begin{abstract}
${ }^{1}$ Enfermeira. Doutoranda no Programa de Pós-Graduação em Enfermagem pela Universidade Federal de Goiás (UFG). Professora Adjunta na Universidade Federal de Mato Grosso (UFMT), Campus Universitário do Araguaia (CUA). Curso de Enfermagem. Barra do Garças, Mato Grosso, Brasil. E-mail: pamela veira@yahoo.com.br ORCID ID: https://orcid.org/0000-0003-0497-6548 Autor principal - Endereço para correspondência: Endereço para correspondência: Av. Valdon Varjão, 6390. CEP 78600-000. Barra do Garças, Mato Grosso, Brasil.

${ }^{2}$ Enfermeira. Residente no Programa de Residência Multiprofissional em Saúde da Família da Universidade Federal de Mato Grosso (UFMT), Campus Universitário de Rondonópolis (CUR). Especialista em Enfermagem do Trabalho pela Faculdades Integradas de Várzea Grande. Barra do Garças, Mato Grosso, Brasil. E-mail: julianazenaro@hotmail.com ORCID ID: https://orcid.org/0000-0002-3819-3368

${ }^{3}$ Enfermeira. Pós-graduada no Programa de Residência Integrada Multiprofissional em Saúde do Adulto e do Idoso com ênfase em Atenção Cardiovascular (PRIMSCAV). Especialista em Cardiologia e Hemodinâmica pela PUC-GO. Barra do Garças, Mato Grosso, Brasil. E-mail: jessenfer@gmail.com ORCID ID: https://orcid.org/0000-0002-9929-4728

${ }^{4}$ Enfermeira. Especialista em Cardiologia e Hemodinâmica. Barra do Garças, Mato Grosso, Brasil. Email: daiana 14@hotmail.com ORCID ID: https://orcid.org/0000-0002-8742-3561

${ }^{5}$ Médico. Pós-Graduado em Psiquiatria. Médico na prefeitura municipal de Pontal do Araguaia. Pontal do Araguaia, Mato Grosso, Brasil. E-mail: rmdgusmao@icloud.com ORCID ID: https://orcid.org/0000-0002-3619-8085

${ }^{6}$ Graduanda em Enfermagem pela Universidade Federal de Mato Grosso (UFMT), Campus Universitário do Araguaia (CUA). Barra do Garças, Mato Grosso, Brasil. E-mail: suzicleia@hotmail.com ORCID ID: https://orcid.org/0000-00022288-9117

${ }^{7}$ Enfermeiro. Mestre. Professor Assistente I na Universidade Federal de Mato Grosso (UFMT), Campus Universitário do Araguaia (CUA). Curso de Enfermagem. Barra do Garças, Mato Grosso, Brasil. E-mail: elefamoso@hotmail.com ORCID ID: https://orcid.org/0000-0002-0086-8286

${ }^{8}$ Enfermeira. Doutoranda em Enfermagem Psiquiátrica pela Escola de Enfermagem de Ribeirão Preto (EERP) da Universidade de São Paulo (USP). Professora Assistente II na Universidade Federal de Mato Grosso (UFMT), Campus Universitário do Araguaia (CUA). Curso de Enfermagem. Barra do Garças, Mato Grosso, Brasil. E-mail: alisseia@hotmail.com ORCID ID: http://orcid.org/0000-0001-6155-6473
\end{abstract}

Este artigo está licenciado sob forma de uma licença Creative Commons Atribuição 4.0 Internacional, que permite uso irrestrito, distribuição e reprodução em qualquer meio, desde que a publicação original seja corretamente citada. 
semiestruturada que foi áudio gravada. Resultados: a partir dos relatos, surgiram as seguintes categorias: descompasso entre o desejo sexual e o risco de gravidez; risco de interrupção da gravidez; a maternagem e seu sentido subjetivo. Assim, verificou-se que a gravidez, para a maioria das adolescentes, não foi planejada, havendo reincidência em duas adolescentes. Além disso, três participantes relataram ter pensado, em algum momento, em interromper a gestação, o que pode estar relacionado a influências de fatores socioculturais. Considerações finais: evidencia-se a importância de facilitar e apoiar o acesso das adolescentes aos serviços de saúde e à informação confiável. Além de priorizar ações que apoiem e valorizem a cultura de paz de modo a prevenir as diversas formas de violência e preconceito contra as jovens mães em todo ciclo gravídico puerperal e, não menos importante, o apoio social adequado durante a gravidez, parto e pós-parto.

Descritores: Gravidez na Adolescência; Planejamento Familiar; Saúde do Adolescente.

\section{ABSTRACT}

Objective: to know the experience of being a mother in adolescence, as well as to identify the sociocultural and emotional inferences that permeate this phase. Method: descriptive and exploratory qualitative approach, developed from the Bardin framework. Data collection took place between January and November of 2013, with ten adolescents living in Barra do Garças-MT, from a semi-structured interview that was audio recorded. Results: From the reports the following categories emerged: mismatch between sexual desire and risk of pregnancy; risk of termination of pregnancy; the mothering and its subjective sense. Thus, it was verified that the pregnancy for most of the adolescents was not planned with recurrence in two of them. Moreover, three participants reported to have thought, at some point, to interrupt the pregnancy, which may be related to influences of sociocultural factors. Final considerations: the importance of facilitating and supporting adolescents' access to health services and reliable information is highlighted. In addition to prioritizing actions that support and value a culture of peace and prevention of various forms of violence and prejudice against young mothers throughout the puerperal pregnancy cycle and, not least, adequate social support during pregnancy, childbirth and post-childbirth.

Descriptors: Pregnancy in Adolescence; Family Planning; Adolescent Health.

\section{RESUMEN}

Objetivo: conocer la experiencia de ser madre en la adolescencia, así como, identificar las inferencias socioculturales y emocionales que impregnaron esta fase. Método: estudio descriptivo, exploratorio de abordaje cualitativo, desarrollado a partir del referencial de Bardin. La recolección de datos ocurrió entre enero a noviembre de 2013, con diez adolescentes residentes en Barra do Garças-MT, a partir de una entrevista semiestructurada que fue audiogravada. Resultados: A partir de los relatos surgieron las siguientes categorías: descompaso entre el deseo sexual y el riesgo de embarazo; riesgo de interrupción del embarazo; la maternidad y su sentido subjetivo. Así, se verificó que el embarazo para la mayoría de las adolescentes no fue planeado, habiendo reincidencia en dos adolescentes y tres participantes relataron haber pensado, en algún momento, en interrumpir la gestación lo que puede estar relacionado a influencias de factores socioculturales. Consideraciones finales: se evidencia la importancia de facilitar y apoyar el acceso de las adolescentes a los servicios de salud y la información confiable, además de priorizar acciones que apoyen y valoren la cultura de paz y la prevención de las diversas formas de violencia y prejuicio contra las jóvenes madres en 
todo ciclo gravídico puerperal y, no menos importante, el apoyo social adecuado durante el embarazo, parto y posparto.

Descriptores: Embarazo en Adolescencia; Planificación Familiar; Salud del Adolescente.

\section{INTRODUÇÃO}

A adolescência é compreendida como o período entre a infância e a fase adulta, marcado por um complexo processo de crescimento e desenvolvimento, tanto biológico, quanto psíquico e social ${ }^{1}$. Para o Ministério da Saúde, são consideradas adolescentes as pessoas cuja faixa etária está entre 10 e 19 anos de idade².

Os adolescentes representam mais de um bilhão, isto é, quase um quinto da população mundial ${ }^{3}$. Dois terços dos nascimentos de filhos e filhas de mães adolescentes (com idade entre 15 e 19 anos) da América Latina e do Caribe ocorrem nos países do Cone Sul (Argentina - Brasil - Chile - Paraguai - Uruguai) ${ }^{4}$.

A taxa de fecundidade elevada entre adolescentes nesta região é de 73,2 por mil mulheres. Comparada com a taxa mundial, que é de 48,9 por mil e, nos países em desenvolvimento, de 52,7 por mil, o número é aproximadamente o dobro das outras regiões, sendo superado apenas pela África, onde o índice chega a 103 por mil ${ }^{4,5}$.

No caso dos países do Cone Sul, ao observar as taxas de fecundidade adolescente entre 2000-2011, diferentes padrões foram identificados. O Brasil, país que apresentava os níveis mais elevados desde o início dos anos 2000 (88,1 por mil mulheres nesse grupo etário), resultado de um aumento registrado durante a década de 1990, viu uma diminuição constante na taxa, chegando a 64,8 por mil mulheres, em 2011, e 60,5, em $2014^{4}$.

No Brasil, entre 2004 e 2014, o registro de nascidos vivos passou de 78,8 para 60,5 filhos por mil mulheres com idade entre 15 e 19 anos, o que indica uma diminuição de $18,4 \%$ para $17,4 \%$, no mesmo período. As taxas brasileiras de gravidez na adolescência são similares às de outros países da América Latina e do Caribe (66,5 por mil mulheres para o período 2010-2015). No entanto, são taxas menores quando comparadas às de países africanos (98,5 por mil). Por outro lado, são bem mais altas que as da Europa (16,2 por mil) e da América do Norte (28,3 por mil) ${ }^{1}$.

Há décadas, a questão da gravidez na adolescência tem sido, cada vez mais, percebida como um desafio crítico para a sociedade moderna. Apesar do crescente interesse de pesquisas sobre as necessidades das mulheres grávidas, as necessidades 
específicas das adolescentes grávidas foram mal atendidas e inadequadamente documentadas 6 .

$\mathrm{Na}$ maioria dos países em desenvolvimento, não existem, no setor público, serviços clínicos adequados para as adolescentes grávidas, incluindo o Brasil. Soma-se ainda, a existência de importantes barreiras que impedem o acesso das adolescentes aos serviços de saúde materna como, por exemplo, os preconceitos sociais e culturais. A incapacidade dos profissionais de abordar essas barreiras e necessidades, ameaça, seriamente, a saúde dessas jovens mães e de seus recém-nascidos, comprometendo ainda mais a taxa de morbimortalidade materna já inaceitavelmente elevada6.

A gravidez na adolescência é, portanto, considerada um problema mundial de saúde pública, pois influencia nos indicadores de saúde de um país devido às suas implicações biológicas, psicológicas, socioeconômicas e familiares ${ }^{7}$. Há diferenças expressivas entre os países - e, em seus interiores, no entanto, há grande probabilidade de que essas diferenças se acentuem quando aproximadas ao nível de urbanização, de escolaridade, de participação feminina no mercado de trabalho e da implementação de políticas públicas no âmbito da saúde sexual e reprodutiva. Por isso, a gravidez na adolescência contribui para consolidar as grandes desigualdades sociais, de gênero, de saúde e econômicas que caracterizam a região ${ }^{4}$.

As adolescentes representam um grupo de alto risco em termos reprodutivos, devido à dupla carga de reprodução e crescimento ${ }^{3}$. Uma gravidez pode ter consequências imediatas e duradouras para a saúde, a educação e para o potencial de renda de uma menina, podendo alterar o curso de sua vida inteira, além de significar maiores riscos de complicações e morte materna ${ }^{4}$.

Igualmente, a gravidez pode interferir no processo de desenvolvimento, uma vez que, resulta em responsabilidades adultas precocemente ${ }^{5}$. Ainda, pode levar ao abandono escolar, a não desenvolver conhecimentos e habilidades importantes e, assim, prejudicar futuras oportunidades de emprego e crescimento econômico. Estudos têm enfatizado que, quando a taxa de natalidade dos adolescentes é alta, a desigualdade de gênero na educação e nos salários é geralmente pior ${ }^{4-7}$.

As normas sociais não só definem um contexto que favoreça ou não a gestação na adolescência, mas também a sua vivência por parte de meninas e meninos. De acordo com o modelo conceitual elaborado na Oficina sobre Gravidez na Adolescência - Voz de Adolescentes e Especialistas ${ }^{1}$, realizada em 2015, em Brasília, a gravidez na 
adolescência pode ser resultante de um ou mais macrofatores causais, a saber: descompasso entre o desejo sexual e o risco de gravidez, que pode resultar na gravidez não planejada ('escapulida'); vontade da maternidade, que resulta na gravidez desejada; necessidade de mudança de status social, que resulta na gravidez estratégica; violência sexual, que resulta na gravidez indesejada².

Esses macrofatores causais podem gerar a gravidez quando combinados com dois fatores condicionantes/intervenientes (status das leis e de sua fiscalização; status das políticas públicas sociais) que, por sua vez, são decisivamente influenciados pelos fatores estruturantes/transversais, sendo eles: concepções e normas sociais relativas a adolescência, sexualidade, casamento e gravidez, as quais estruturam preferências, comportamentos, atitudes e práticas sociais das crianças e adolescentes, de seus familiares e dos profissionais e agentes que realizam a intervenção social junto às meninas e às adolescentes grávidas ${ }^{1}$.

Diante da problemática, emergiu o Marco Estratégico, documentado na "Estratégia regional para prevenção e redução da gravidez não intencional na adolescência"4, publicado em junho de 2017, como resultado de um amplo processo de trabalho conjunto iniciado no ano de 2015. A ação envolveu autoridades e funcionários públicos dos Ministérios da Saúde, Educação e Desenvolvimento Social da Argentina, Brasil, Chile, Paraguai e Uruguai, assim como funcionários do Fundo de População das Nações Unidas (UNFPA), Organização Pan-Americana da Saúde (OPAS), Fundo das Nações Unidas para a Infância (UNICEF) e acadêmicos/as especialistas na temática4 ${ }^{4}$.

Sobre os temas que englobam a saúde dos adolescentes e dos jovens, principalmente saúde sexual e reprodutiva, o Brasil tem alguns marcos normativos como a Política Nacional de Atenção Integral de Adolescentes e de Jovens, que garante o direito à saúde dos adolescentes no Sistema Único de Saúde. A Lei 9.394 de Diretrizes e Bases da Educação Nacional, de 1996, sugere abordar a educação sexual como um assunto transversal relacionado aos conteúdos de disciplinas e atividades extracurriculares ${ }^{8,9}$. Ademais, cita-se o Decreto $6.286 / 2007^{5}$, que regulamenta o Programa Saúde na Escola (PSE): uma política intersetorial dos Ministérios da Educação e da Saúde com o objetivo de contribuir com a formação integral dos alunos do ensino público básico, por meio de ações de prevenção, promoção e atenção à saúde, inclusive saúde sexual e reprodutiva ${ }^{5}$. 
A ocorrência da gestação durante a adolescência pode assumir diferentes significados para as jovens que a vivenciaram. Fatores sociais, econômicos e culturais são aspectos que influenciam e ajudam a entender como a gestação é sentida por cada adolescente ${ }^{10}$.

Por isso, conhecer as nuances da gestação na adolescência e suas inferências, segundo o relato de quem a vivencia, é um desafio importante aos profissionais da equipe interdisciplinar de saúde, uma vez que os convida a uma análise crítica sobre as potencialidades e as lacunas existentes na atuação desses sujeitos no contexto das políticas públicas de saúde voltadas aos adolescentes. Além disso, permite a esses profissionais conhecer as consequências na saúde, na educação e na economia da população brasileira, além de ser um grande desafio para satisfazer adequadamente as necessidades educacionais, informativas e clínicas das mulheres adolescentes.

Diante da importância da temática exposta, as perguntas condutoras desta pesquisa foram: como a adolescente vivenciou a gravidez? Quais as implicações socioculturais e emocionais que permearam esta experiência?

Assim, objetivou-se conhecer a experiência de ser mãe na adolescência, bem como, identificar as inferências socioculturais e emocionais que permearam essa fase.

\section{MÉTODO}

Estudo descritivo, exploratório, de abordagem qualitativa, realizado com 10 adolescentes residentes no município de Barra do Garças, Mato Grosso, Brasil. As jovens foram escolhidas aleatoriamente entre as 921 Declarações de Nascidos Vivos (DN) de mães adolescentes registradas no ano de 2012.

De acordo com os critérios de elegibilidade, foram incluídas na pesquisa as adolescentes na faixa etária de 10 a 19 anos, que tiveram seus filhos em um hospital público municipal, no ano de 2012, não importando o número de filhos anteriores ou o tipo de parto.

A pesquisa em campo foi realizada nos meses de janeiro a novembro de 2013, mediante a disponibilidade das adolescentes. A coleta de dados foi realizada por meio de entrevista semiestruturada baseada em roteiro com questões abertas e fechadas. Foram incluídas características sociodemográficas (idade, escolaridade, estado civil e profissão/ocupação), temas relacionados à primeira gestação (idade da primeira 
gestação, o número de filhos, o tipo de parto e o planejamento familiar) e aos aspectos socioculturais e emocionais (percepções e concepções sobre a gestação na adolescência).

As entrevistas foram individuais, audiogravadas com a autorização das participantes e de seus responsáveis legais. Foram realizadas na residência das adolescentes, de acordo com data e horário pactuados entre participante e pesquisador. Após a conclusão das entrevistas, houve a transcrição, na íntegra, de todas as narrativas, aplicando a análise de conteúdo e modalidade temática proposta por Bardin $^{11}$.

Primeiramente, as entrevistas foram submetidas a várias leituras, com formulação e reformulação de hipóteses e objetivos, tendo como parâmetro a leitura exaustiva do material e as indagações iniciais. No segundo momento, realizou-se a exploração do material para alcançar o núcleo de compreensão do texto, ou seja, encontrar as categorias, que são expressões ou palavras significativas em função das quais o conteúdo de uma fala seria organizado ${ }^{11}$. Essas categorias surgiram pelos critérios da repetição e da relevância. Emergiram três categorias temáticas: descompasso entre o desejo sexual e o risco de gravidez; risco de interrupção da gravidez; maternagem e seu sentido subjetivo.

Para cada narrativa da adolescente utilizou-se codificação do tipo alfanumérica, de modo que a letra "P" indica a Participante, e o elemento número que compõe apenas indicou a posição do discurso no desenvolvimento da análise (ex: P1, P2, .. P10).

Este trabalho é um desdobramento da pesquisa intitulada "Adolescência: Gestação, Parto e Puerpério". Os dados foram coletados após a aprovação do Comitê de Ética e Pesquisa da Universidade Federal de Mato Grosso, sob CAAE: 01742112.1.0000.5541 e Parecer Consubstanciado $n^{\circ}$ 69351, de 08 de agosto de 2012, tendo sido respeitados rigorosamente todos os princípios e as diretrizes éticas de pesquisa envolvendo seres humanos, em atendimento à Resolução 466/2012 do Conselho Nacional de Saúde. Todos os participantes aceitaram participar do estudo por meio da assinatura do Termo de Consentimento Livre e Esclarecido (TCLE).

\section{RESULTADOS E DISCUSSÃO}


O IBGE descreveu as seguintes características da população de adolescentes entre 15 e 19 anos que tinham, ao menos, um filho nascido vivo em 2014: 65,9\% de meninas entre 18 e 19 anos de idade; 69\% das meninas eram negras (pretas ou pardas); $59,7 \%$ das meninas não trabalhavam/estudavam e 92,5\% cuidavam dos afazeres domésticos; 37,1\% estavam na condição de filha na unidade domiciliar e 34,2\% estavam na condição de cônjuge; 35,8\% das jovens residiam na Região Nordeste ${ }^{1}$.

Neste estudo, inicialmente, buscou-se caracterizar as participantes com dados relativos à idade, à escolaridade, ao estado civil e à profissão/ocupação.

A idade das adolescentes foi de 16 a 19 anos, sendo que a média de idade foi de 18 anos. Em relação ao nível de escolaridade, 50\% possuíam o Ensino Médio Completo, 40\% não completaram o Ensino Médio e 10\% possuíam o Ensino Fundamental Incompleto.

No que diz respeito ao estado civil, nota-se que $80 \%$ eram solteiras e $20 \%$ estavam em uma união estável. Dados semelhantes foram encontrados em estudos realizados no Brasil, no estado de Minas Gerais e no Ceará, nos quais a maioria das participantes eram mães solteiras ${ }^{12,13}$.

Ser solteira ou não ter companheiro como fator de risco para a gravidez não constitui um achado surpreendente, visto que uma gestação sem uma estrutura familiar não é uma condição patológica em si, mas uma problematização sociocultural ampla e que merece mais atenção ${ }^{14}$. Ainda, o estado civil pode ser relacionado a um sinal de desigualdade entre os sexos, o que afeta as decisões da mulher em relação à sua autonomia reprodutiva. Isso também é confirmado pela Organização Mundial da Saúde OMS e pelo Fundo de População das Nações Unidas (UNFPA) ${ }^{4-6}$.

Além disso, outro estudo retrata a realidade das adolescentes que mantêm uma união estável iniciada em decorrência do nascimento dos filhos, geralmente, por pressão ou obrigação. Esse fato cria laços fragilizados e suscetíveis à dissolução, o que, a longo prazo, pode constituir-se como desvantagem para as mulheres do ponto de vista econômico e educacional ${ }^{15}$.

Sobre a ocupação/profissão, 40\% das participantes não trabalhavam fora de casa, 30\% eram estudantes e 30\% trabalhavam fora do seu domicílio (exercendo as profissões de atendente, garçonete e técnico administrativo).

Nesse ponto, é importante salientar que os partos de adolescentes estão intimamente relacionados à desigualdade de renda e à incidência da pobreza. As altas taxas de natalidade têm sido associadas à redução da atividade econômica das mulheres 
- especialmente por adolescentes -, que, depois de engravidar, frequentemente deixam a escola, prejudicando seu potencial futuro à medida que entram no mercado de trabalho. As altas taxas de natalidade dos adolescentes podem, portanto, aumentar a desigualdade na educação, na participação econômica e no potencial de lucro ${ }^{4-7}$.

As adolescentes também foram questionadas sobre a idade da primeira gestação, o número de filhos, o tipo de parto e o planejamento familiar. A média da idade da primeira gestação foi de 17 anos. Em relação ao número de filhos, a média foi de 1 por adolescente. O tipo de parto foi $60 \%$ cesariana e $40 \%$ vaginal. Esse fato foi apontado como negativo, pois o primeiro parto da adolescente sendo uma cesariana pode causar prejuízos como o aumento da possibilidade de complicação nas gestações subsequentes, placentação anômala e morbimortalidade neonatal, havendo maior probabilidade à medida que aumenta o número de cesarianas anteriores ${ }^{16}$. Além disso, há uma tendência de se privilegiar a via do parto anterior nas gestações subsequentes ${ }^{16}$.

Acrescenta-se ainda que as complicações decorrentes da gravidez e do parto são a principal causa de morte entre adolescentes de 15 a 19 anos em todo o mundo. 0 risco de morte materna para mães menores de 15 anos em países de baixa e média renda é o dobro das mulheres mais velhas. Além disso, esse grupo enfrenta taxas significativamente maiores de fístulas obstétricas ${ }^{6,7}$.

\section{Descompasso entre o desejo sexual e o risco de gravidez}

O planejamento familiar é essencial para assegurar a maternidade segura, reduzindo as gravidezes indesejadas ${ }^{4-6}$. 0 planejamento familiar no Brasil é regulamentado pela Lei $n^{\circ}$ 9.263/1996, que, embora não mencione os adolescentes, assegura a todos os cidadãos a assistência à concepção e à contracepção e a assistência ao parto, ao puerpério e ao neonato, entre outras providências ${ }^{17}$.

Estudos realizados no Paraguai identificaram dados importantes, em que: 86,8\% das adolescentes não usaram anticoncepcionais ${ }^{18} ; 44,9 \%$ dos partos de adolescentes de 15 a 19 anos foram consequências de gravidezes não planejadas, podendo ser inoportunas $(41,8 \%)$ ou indesejadas $(3,1 \%)^{19}$. A idade das mães e os anos de educação foram associados a partos inoportunos. 
Convergindo com este contexto, neste estudo, a maioria das participantes afirmaram que não planejaram a sua gestação e receberam a notícia com surpresa, 0 que pode ser evidenciado na fala a seguir.

Do primeiro filho foi, da segunda foi por acidente [...] o meu primeiro filho estava com quatro meses quando fiquei grávida dela. (P1)

Não obstante, um estudo realizado na Argentina com mães adolescentes $(n=1.645)$, utilizando a técnica de grupos focais, revelou que a maioria das participantes da pesquisa (82\%) não usavam método anticoncepcional no momento em que engravidaram. As principais razões para não terem utilizado foi por pensarem que não podiam engravidar (19\%), pela falta de informação sobre o acesso a anticoncepcionais (11\%), pela relação sexual inesperada (10\%) e pela recusa de uso de anticoncepcionais dos parceiros $(7 \%)^{20}$.

No presente estudo, as adolescentes participantes surpreenderam-se com a gravidez, por não ser planejada e por acreditarem, de algum modo, que isso não aconteceria com elas. Percebe-se que esse tipo de atitude atua como uma dissociação entre a prática sexual e a gravidez, ou seja, reafirma o descompasso entre o desejo sexual e o risco de gravidez, o que explica o motivo de as adolescentes ficarem surpresas quando a gravidez é confirmada. A fala a seguir apresenta essa questão.

Não, foi um susto, na verdade, porque a minha irmã já estava grávida e depois descobri, logo em seguida. (P2)

A fala da participante converge com achados de uma coorte que envolveu 17.115 mulheres nascidas em Manitoba, no Canadá, entre 1 de abril de 1979 e 31 de março de 1994 e que permaneceram na província até, pelo menos, 20 anos de idade. A investigação revelou que as probabilidades de uma adolescente engravidar, com, pelo menos, uma irmã mais velha com gravidez na adolescência, foram 3,38 (99\% IC 2,774,13) vezes maior do que em mulheres cuja irmã mais velha não teve gravidez na adolescência. As filhas adolescentes de mães que tiveram seu primeiro filho antes dos 20 anos tinham 1,57 (99\% IC 1,30-1,89) vezes maiores chances de gravidez do que aquelas cujas mães tiveram seu primeiro filho após os $19 \operatorname{anos}^{21}$.

Nesse contexto, uma outra coorte realizada no Chile, com o objetivo de examinar o padrão intergeracional de gravidez na adolescência em filhas de mulheres 
que foram mães adolescentes, revelou que $21 \%$ dessas filhas repetiram a gravidez na adolescência22.

A gravidez não planejada, inesperada ou inoportuna relatada pelas adolescentes participantes deste estudo também foi evidenciada em outros estudos, como por exemplo, uma pesquisa realizada em Minas Gerais (Brasil), onde 67\% das adolescentes grávidas não planejaram a gestação ${ }^{12}$ e no Rio Grande do Sul (Brasil), em 2007, que identificou a prevalência de $65 \%$ de gravidez não planejada entre as participantes. Além disso, evidenciou que, quanto mais jovens são as mulheres, maior é a associação com a gravidez não planejada ${ }^{14}$.

Todos os anos, nos países em desenvolvimento, existem 89 milhões de gravidezes não planejadas, e 12,8 milhões de adolescentes têm uma demanda insatisfeita de planejamento familiar(4). Ainda, uma rápida sucessão de gestações pode obstar a entrada ou a permanência da mulher em um trabalho remunerado, afetando suas expectativas, de longo prazo, de garantir uma boa remuneração - o que também foi evidenciado em algumas falas das participantes.

Eu trabalhava, aí perto de ganhar ele eu parei" (P3). "Tive que deixar o emprego...mudou tudo. (P4)

Nota-se que houve reincidência de gravidez em duas adolescentes e uma dessas adolescentes afirmou que a gravidez de seu primeiro filho foi planejada, tendo como motivação o sentimento em relação ao pai da criança. Já o segundo filho não foi planejado.

Do primeiro filho foi (planejada), eu gostava muito do pai dele [...] da segunda foi por acidente. (P1)

Nenhuma das duas foi planejada. (P5)

Em outros estudos, também foi destacada a relevância da reincidência da gravidez na adolescência. Um estudo realizado com 204 adolescentes no município de Caruaru - PE (Brasil), constatou que 26,5\% das jovens eram multigestas e apresentaram elevada taxa de ocorrência de reincidência de gestação rápida, com uma prevalência de 42,6\%, em que uma alta parcela das adolescentes teve uma nova gestação em menos de dois anos a partir da sua última gravidez ${ }^{11}$. Já um outro estudo realizado na Inglaterra revelou uma taxa de gravidez subsequente em $66 \%$ das adolescentes acompanhadas em 
uma coorte, aproximando os achados a um desafio de saúde pública que permanece sem solução ${ }^{23}$.

Confirmando os achados, um estudo realizado no município de Aragarças - GO (Brasil), que faz divisa com o município Barra do Garças - MT, onde foi realizado o presente estudo, revelou a reincidência da gravidez em cerca de $40 \%$ das entrevistadas $^{12}$. Esse fator de reincidência de gravidez converge com os dados evidenciados nesta pesquisa, pois uma das adolescentes trocou de parceiro após o nascimento do primeiro filho, engravidando, novamente, de outro parceiro após quatro meses.

Nesse contexto, é imprescindível que os profissionais de saúde voltem seus olhares para o fortalecimento de ações e comunicações que assegurem o direito reprodutivo e sexual das adolescentes, incluindo a contracepção de emergência.

Sobre a contracepção de emergência, resultados de um estudo realizado no Chile, em janeiro de 2010, após a aprovação da Lei 20.418, que restabeleceu a prestação de anticoncepção de emergência (pílula no dia seguinte) no serviço de saúde pública do país, identificou que a taxa média de consulta para contracepção de emergência em adolescentes atinge 4,27 mulheres adolescentes entre 15 e 19 anos. Essa taxa é quase o dobro comparado com mulheres de 15 a 44 anos. Além disso, os maiores níveis de demanda estão relacionados com indicadores socioeconômicos deficientes ${ }^{24}$.

$\mathrm{O}$ acesso à escolha de métodos de planejamento familiar seguros, acessíveis e adequados é essencial à saúde das mães adolescentes ${ }^{4-6}$. Assim, 0 acesso ao planejamento familiar pelas adolescentes se baseia em um enfoque de direitos, já que “especialmente quando não é fruto de planejamento e desejo, é uma clara manifestação de vulnerabilidade dos direitos sexuais e reprodutivos das adolescentes e, portanto, de seus direitos humanos"4,7.

\section{Risco de interrupção da gravidez}

Outro aspecto que não é dissociável do planejamento familiar é o risco de aborto entre adolescentes grávidas. Neste estudo, três participantes relataram não aceitar a gravidez e pensaram, em algum momento, na possibilidade de aborto, conforme pode ser verificado nas falas. 
Eu não queria não (ter um filho). (P6)

Eu pensei em tirar. (P7)

O número mundial de abortos entre adolescentes varia de 2,2 a 4 milhões por ano ${ }^{(4-6)}$. Devido às restrições legais e sociais sobre o acesso a abortos em muitas partes do mundo, incluindo no Brasil, as adolescentes frequentemente recorrem a procedimentos inseguros administrados por clínicas ilegais e profissionais não qualificados ${ }^{6}$.

De acordo com a Pesquisa Nacional de Aborto de 2016 (PNA 2016), que realizou um inquérito domiciliar com 2.002 mulheres com idade entre 18 e 39 anos no Brasil, 13\% (251) já fez, ao menos, um aborto. Além disso, há uma frequência maior do último aborto entre as mulheres jovens, com 29\% (73) dos abortos ocorrendo em idades que vão de 12 a 19 anos, 28\% (70) dos 20 aos 24 anos, caindo para abaixo de 13\% (32) a partir dos 25 anos $^{25}$.

0 aborto inseguro, caracterizado como um evento negligenciado, configura-se um importante problema de saúde pública nos países do Cone Sul, visto que pode estar relacionado, entre outros fatores, com regiões socioeconomicamente mais pobres de um país $^{4-7}$.

Ainda, um outro estudo realizado na Bahia, em 2001, em um "Hospital Amigo da Criança”, revelou que a maior frequência de aborto foi entre adolescentes de 17 a 19 anos, sendo $81,6 \%$ solteiras. 0 aborto provocado, bem como o aborto ignorado foram mais frequentes, $55,2 \%$ e $30,4 \%$, respectivamente ${ }^{26}$.

Sobre a interrupção da gravidez nos países do Cone Sul, no Brasil e na Argentina, mesmo que a legislação contemple situações em que o aborto não é punido, o acesso à prática é dificultado. Segundo estatísticas, a proibição da interrupção voluntária da gravidez não impede que uma adolescente realize um aborto em condições clandestinas. Especificamente no Brasil, só está descriminalizado o aborto por risco de vida à mãe, estupro e inviabilidade fetal (para os casos de anencefalia fetal) ${ }^{4,5}$.

Um estudo retrospectivo que revisou histórias clínicas de adolescentes no período entre 2012-2014, em um Hospital de Ensino na América Central, identificou que a principal causa do pedido de interrupção da gravidez foi a necessidade de continuar estudos: $38,4 \%$. As adolescentes entre 17 e 18 anos representaram o maior número de $\operatorname{casos}^{27}$. 
Sobre alguns aspectos qualitativos do aborto em adolescentes, discussões em grupos focais realizadas por um estudo na Argentina, revelaram que a opção pelo aborto está mais relacionada à vergonha e ao medo das reações dos pais do que com uma rejeição direta da maternidade. Assim, esse procedimento surge como solução para evitar a tensão com os adultos ${ }^{20}$.

No mesmo estudo citado acima, embora o aborto esteja legalmente restrito na Argentina, cerca de 5\% das participantes da pesquisa disseram ter um aborto, das quais $62 \%$ foram na primeira gravidez; $29 \%$, na segunda; $8 \%$, na terceira e $1 \%$ na quarta gravidez.

\section{A maternagem e seu sentido subjetivo}

Em um segundo momento, as adolescentes expressaram seus sentimentos, dificuldades e positividades sobre "Ser mãe na adolescência". Emergiram dos relatos das participantes os desafios enfrentados, com todas as implicações socioculturais que as permeiam. É nesse cenário de insegurança e imaturidade física e emocional que se revelam as múltiplas implicações da gestação precoce.

Após o nascimento de uma criança, a vida da mãe muda completamente, pois, a partir daquele momento ela, obrigatoriamente, adquirirá uma série de novas tarefas com prazos determinados e inadiáveis, como por exemplo, amamentar ou alimentar com formulas lácteas, cuidados higiênicos com o bebê, fazer ninar, brincar, enfim, uma série de novas responsabilidades inerentes à mãe e/ou à família (mãe e pai), que só aumenta com o passar dos anos.

Acredita-se que, para uma adolescente deixar de lado a maior parte de suas tarefas e de seu lazer e começar uma vida cheia de novas tarefas e regras, é necessária uma adaptação, que nem sempre é fácil, pois, para algumas jovens habituadas a uma rotina "sem/com poucas regras", "sem/com poucas tarefas" ou "sem/com poucos limites”, ter um filho é uma mudança muito significativa, tornando-se um tanto quanto mais imperativo o termo "responsabilidade", como evidenciado na fala abaixo. 
Algumas adolescentes afirmaram não possuir responsabilidade acerca de sua própria vida, o que implica no sentimento de insegurança para cuidar de si e de seu filho.

Só assim que eu descobri ter mais responsabilidade [...] Porque antes eu não tinha [...] Nem comigo mesmo. (P2)

[...] é meu filho, mas quem cuida mesmo é minha mãe. (P8)

As adolescentes tornam-se vulneráveis à gravidez devido a uma série de aspectos, dentre eles, o que mais se destaca é o fato de a mãe adolescente, na maioria das vezes, não estar preparada para cuidar do seu filho devido à falta de experiência e à imaturidade, no sentido de não dominar os cuidados a serem adotados com os filhos ${ }^{28}$.

Essa falta de experiência e puerilidade foi reconhecida pela própria adolescente quando ela menciona "não ter responsabilidade" para cuidar de um bebê. Evidencia-se uma incerteza, um desconhecimento do "estar gravida" ou do que seria aquela gestação e o que estaria por vir após o nascimento da criança. Assim, o "não ter responsabilidade" também está relacionado ao desconhecimento da vivência e por ter que vivenciá-la tão precoce, pois a jovem está precisando ser cuidada e não se vê preparada para cuidar de outro ser.

Além disso, há o desconhecimento, ou seja, não ter conhecimento ou informações a respeito de algum objeto ou alguma situação. Esse sentimento foi observado nas falas a seguir.

É um pouco complicado [...] A gente sem nenhum preparo de como ser mãe [...] Porque muitos pais não conversam sobre isso na adolescência. (P4)

Como mencionado pela adolescente, o sentimento de desconhecimento de “como ser mãe" está, por ela relacionado, ao fato de os pais não conversarem com suas filhas a respeito dessa temática.

No entanto, vale ressaltar que nenhum pai ou mãe, deseja ensinar uma filha, ainda tão jovem, a ser mãe. Portanto, o que não pode faltar no diálogo entre pais e filhos são assuntos inerentes aos métodos que a(o) filha(o) pode fazer uso para evitar uma gravidez inoportuna/inesperada.

Sobre isso, pesquisadores no Chile verificaram que, embora as mães das adolescentes declarassem que não queriam que suas filhas ficassem grávidas, não conseguiram falar sobre a sexualidade com elas ou transmitir mensagens adequadas para 
desencorajar sua atividade sexual. Ainda, ao analisar as características das filhas que ficaram grávidas versus suas mães, observou-se que as filhas ficaram grávidas em idades mais jovens, apresentaram condições familiares mais desfavoráveis e tiveram mais parceiros sexuais do que suas mães ${ }^{22}$.

O desconhecimento em relação à nova situação foi acompanhado por sentimentos de aceitação e de negação.

Não tenho cabeça pra isso não, às vezes a ficha não cai[...]. (P8)

Eu não sei, ainda não caiu a ficha que eu sou mãe de dois filhos não. (P1)

Não obstante, outro estudo destaca que a gravidez é geradora de mais vergonha entre as meninas do que entre os meninos, os quais encaram a gravidez como motivo de preocupação e necessidade de procurar trabalho. Já as meninas encaram a gravidez como algo "mais errado" e, assim, geradora de vergonha, possivelmente pela ocorrência de desvelar uma sexualidade existente, mas nem sempre lícita, com exposição a relações sexualmente desprotegidas ${ }^{(14)}$, conforme pode ser verificada nas falas.

Porque mãe solteira com filho é meio complicado. (P4)

Fiquei doida, né, fiquei com medo de alguém me julgar, de falar alguma coisa, de não aceitar. (P8)

Nossa, muita gente critica muito, muita mãe de amigos fica muito chateada até pede pra poder afastar. (P5)

O sentimento de impedimento e interferência emergiu nas falas das participantes, como se a gravidez estivesse as impedindo de viver e gozar dos benefícios e prazeres da adolescência. Quando se fala em impedimento, refere-se a um obstáculo, a alguma situação que impede de vivenciar aquilo que se deseja, conforme pode ser verificado nas falas.

Empata muito a vida da gente um filho. (P1)

É uma fase muito difícil [...] A gente quer mais sair, quer curtir a vida, tá começando a ter liberdade [...]. (P5)

O sentimento de prazer se refere a sentir-se bem (bem-estar), a alegrar-se em relação a alguém ou alguma situação específica. Este sentimento foi evidenciado também na pesquisa.

Eu acho bom [...] Eu não sei por que, é interessante, não é questão de idade que eu possa me arrepender, eu acho bom. (P9) 
Embora a gravidez na adolescência seja apontada como um evento negativo e responsável por desarranjos na vida das jovens, em algumas situações, gestar na adolescência constituiu uma possibilidade de busca da autonomia e da responsabilidade, no desejo consciente de ser mãe e, até mesmo, em uma fonte de satisfação ${ }^{28}$.

Outro estudo também revelou o sentimento de prazer e a visão da gravidez como algo bom para a vida das meninas, ou seja, a gravidez foi descrita como um episódio positivo, porém com vivências negativas ${ }^{29}$.

A gravidez na adolescência não pode ser somente relacionada aos impactos negativos quanto às perspectivas de vida das jovens, ela pode ser desejada, pois é tida como uma via de acesso a uma nova identidade, além do reconhecimento por meio do papel materno ${ }^{1}$.

Além disso, a maternidade pode ser compreendida como uma ocupação, um papel que dá um sentido à vida da jovem. A falta de outros projetos de vida ou frente à dificuldade em vislumbrar a possibilidade de efetivar planos alternativos, a gravidez pode ser percebida pela adolescente como uma forma de reconhecer a si mesma, de marcar seu próprio espaço na família e de ser reconhecida nos seus ambientes de convívio ${ }^{30}$.

No que se refere às dificuldades, observa-se que elas podem ser sociais, emocionais e familiares. Enfrentar uma sobrecarga de transformações torna penosa e difícil a tarefa de ser mãe adolescente. O sentimento de vivenciar um momento permeado de diferentes dificuldades foi apresentado por todas as participantes do estudo, conforme expressado nas narrativas.

Com sinceridade? É muito difícil, você não tem responsabilidade, então você não sabe nem pra onde vai, complica. Empata muito a vida da gente ter um filho (P9).

É difícil, assim no começo eu fiquei apavorada. (P6)

É uma fase muito difícil... a gente quer mais sair, quer curtir a vida [...]. (P5)

É difícil por conta que agora eu trabalho né, e eu tenho que deixar ela com minha mãe. (P10)

Pra mim foi difícil porque meus pais são crentes. (P3)

A necessidade de conciliar a vivência da própria adolescência, considerada uma época de desafios e definições individuais, com o papel parental é apontada como a principal dificuldade enfrentada pelas jovens ${ }^{29}$.

A dificuldade expressada em ser mãe na adolescência pode estar relacionada a uma gestação conflituosa. A adolescente pode se sentir frustrada e decepcionada diante 
da nova situação imposta. Os objetivos projetados para si são adiados diante da necessidade de cuidar de um novo ser. Ao olhar para o filho ela pode lembrar de tudo que perdeu ou que gostaria de fazer e que agora não pode. Esse fato pode justificar o motivo de a jovem não apresentar sentimento de carinho e ternura pelo filho.

\section{CONSIDERAÇÕES FINAIS}

A gravidez, para a maioria das adolescentes participantes, não foi planejada e a notícia foi recebida com surpresa. Esse fato pode ser explicado pelo sentimento de imunidade que a adolescência traz, pelo descompasso entre o desejo sexual e o risco de gravidez, levando a jovem ao sexo desprotegido da concepção e a consequente gravidez.

Nota-se também ter havido reincidência da gravidez em duas adolescentes, sendo que três participantes relataram ter pensado, em algum momento, na interrupção da gestação. Isso pode estar relacionado a influencias de fatores socioculturais (preconceito, inconclusão do ensino médio ou fundamental, ausência de formação profissional, dificuldades para inserção e permanência no mercado de trabalho, fragilidades relacionadas ao convívio familiar e com o pai da criança, diminuição do lazer e da liberdade, agregação de compromissos e responsabilidades, insegurança financeira) e pelas subjetividades individuais que permeiam a gestação (inseguranças e dificuldades nos desempenho da maternagem, medos, sonhos, decepções, adaptação, satisfação e felicidade).

Essas implicações que permeiam a experiência de ser mãe na adolescência ajudam a compreender as nuances desse fenômeno segundo as concepções de quem o vivencia. Portanto, são pontos de alavancagem para as intervenções dos profissionais da equipe multidisciplinar de saúde dos países do Cone Sul e podem sugerir e/ou determinar as prioridades de intervenção estreitamente ligadas à saúde das adolescentes, principalmente no âmbito da saúde sexual e reprodutiva e do ciclo gravídico puerperal. Além disso, sugere-se aos profissionais de saúde intervenções flexíveis e apropriadas ao contexto sociocultural no qual a jovem está inserida.

Nesse cenário, evidencia-se a importância de facilitar e apoiar o acesso das adolescentes aos serviços de saúde e à informação confiável, além de priorizar ações que apoiem e valorizem a cultura de paz e a prevenção das diversas formas de violência 
e preconceito contra as jovens mães em todo ciclo gravídico puerperal e, não menos importante, o apoio social adequado durante a gravidez, parto e pós-parto.

Finalmente, sugere-se que um modelo de programa único não pode atender a demandas tão singulares e complexas, principalmente em países do Cone Sul. Assim, reforça-se a importância de planejar e executar modelos de atenção à saúde pensados à luz dos recursos disponíveis nos países, adaptados aos contextos sociais e culturais e, principalmente, construídos e enriquecidos com as vivências, concepções e percepções das próprias adolescentes.

\section{REFERÊNCIAS}

1. Santos BR, Magalhães DR, Mora GG, Cunha A. Gravidez na Adolescência no Brasil Vozes de Meninas e de Especialistas. Instituto dos Direitos da Criança. Brasília: INDICA; 2017.

2. Fiedler MW, Araújo A, Souza MCC. A prevenção da gravidez na adolescência na visão de adolescentes. Texto \& contexto enferm. 2015; 24(1):30-7.

3. Talawar S, Venkatesh G. Outocome of Teenage Prenancy. J dent med sci. 2013; 6(6):81-3.

4. Fundo de População das Nações Unidas para a América Latina e o Caribe (UNFPA LACRO). Estratégia regional para prevenção e redução da gravidez não intencional na adolescência: uma aliança sub-regional para avançar com a implementação das políticas no cone sul. Cone Sul: Argentina, Brasil, Chile, Paraguaia, Uruguai. Assunção; 2017.

5. Fundo de População das Nações Unidas (UNFPA). UNFPA América Latina e Caribe. Fecundidade e Maternidade Adolescente no Cone Sul: Anotações para a Construção de uma Agenda Comum. Assunção: UNFPA; 2016.

6. WHO. World Health Organization. Adolescent pregnancy: unmet needs and undone deeds: a review of the literature and programmes. Genebra: WHO; 2007.

7. United Nations Population Fund (UNFPA). The State of World Population 2017. Worlds Apart: Reproductive health and rights in an age of inequality. Acesso em 2018 Ago 12. Disponível em: https://www.unfpa.org/swop.

8. Ministério da saúde (BR). Diretrizes nacionais para a atenção Integral a saúde de Adolescentes e de Jovens. Brasília: Ministério da Saúde; 2010. 
9. Brasil. Lei de Diretrizes e Bases da Educação Nacional. Brasília: Senado Federal; 2017.

10. Dias ACG, Jager ME, Patias ND, Oliveira CT. Maternidade e casamento: o que pensam as adolescentes? Rev J Interacções. 2013; 9(25): 90-112.

11. Bardin L. Análise de conteúdo. São Paulo: Edições 70; 2011.

12. Jezo RFV, Ribeiro IKS, Araújo A, Rodrigues BA. Gravidez na adolescência: perfil das gestantes e mães adolescentes em uma Unidade Básica de Saúde. Rev enferm Cent.-Oeste Min. 2017; 7:1-8.

13. Queiroz MVO, Menezes GMD, Silva TJP, Brasil EGM, SILVA RM. Grupo de gestantes adolescentes: contribuições para o cuidado no pré-natal. Rev gaúch enferm. 2016; 37(esp):1-7.

14. Prietsch SOM, González-Chica DA, Cesar JA, Mensonza-Sassi RA. Gravidez não planejada no extremo Sul do Brasil: prevalência e fatores associados. Cad saúde pública. 2011; 27(10):1906-16.

15. Rodrigues MP, Nascimento CMBV, Melo RHV, Oliveira DA, Ferreira MAF, Oliveira AP. Percepções sobre os efeitos psicossociais da gravidez na adolescência no cenário da Estratégia Saúde da Família. Rev Ciênc Plur. 2017; 3(1):81-97.

16. Gama SGN, Viellas EF, Schilithz AOC, Theme Filha MM, Carvalho ML, Gomes KRO, et al. Fatores associados à cesariana entre primíparas adolescentes no Brasil, 20112012. Cad saúde pública. 2014; 30:117-27.

17. Brasil. Lei $n^{\circ} 9.263$, de 12 de janeiro de 1996. Planejamento Familiar. Brasília; 1996.

18. Cabanas A, Mercedes B, Salinas E, Sebastian J. Embarazo adolescente em um hospital de Paraguay durante el 2011. Horiz méd. 2016; 16(2):40-4.

19. Melian MM. Intenciones reproductivas y factores asociados con los nacimientos no planeados, Paraguay, 1995-2008. Rev panam salud pública. 2013; 33(4):244-51.

20. Gogna, M. Adolescent pregnancy in Argentina: evidence-based recommendations for public policies. Reprod health matters. 2008; 16(31):192-201.

21. Wall-Wieler E, Roos LL, Nickel NC. Teenage pregnancy: the impact of maternal adolescent childbearing and older sister's teenage pregnancy on a younger sister. BMC pregnancy childbirth. 2016; 16(120):1-12.

22. González EA, Leal IF, Molina TG, Chacón PC. Patrón intergeneracional del embarazo adolescente en las hijas de una cohorte de mujeres que controlaron su 
primer embarazo en un centro integral para adolescentes embarazadas. Rev chil obstet ginecol. 2013; 78(4):282-9.

23. Robling M, Bekkers MJ, Bell K, Butler CC, Cannings-John R, Channon S, et al. Effectiveness of a nurse-led intensive home-visitation programme for first-time teenage mothers (Building Blocks): a pragmatic randomised controlled trial. Lancet. 2016; 9(387):146-55.

24. Moran Faundes, JM. La anticoncepción de emergencia en Chile: estructuración de su demanda en función de variables socioeconómicas. Rev bras estud popul. 2013; 30(1):125-144.

25. Diniz D, Medeiros M, Madeiro A. Pesquisa Nacional de Aborto 2016. Ciênc Saúde Colet. 2017; 22(2): 653-60.

26. Souza VLC, Correa MSM, SOUZA SL, BESERRA MA. O aborto entre adolescentes. Rev latino-am Enfermagem. 2001; 9(2):42-47.

27. Izaguirre BMH, Argudín EH, Naranjo DR, Trabanco MEE, Llerena FR. Causas de interrupción de embarazo en adolescentes. Hospital Docente Materno "10 de Octubre". Rev urug enferm. 2017; 12(1):60-8.

28. Spindola T, Oliveira ACFC, Cavalcanti RL, Fonte RF. Amamentação na adolescência: histórias de vida de mães primíparas. Rev pesqui cuid fundam. 2014; 6(1):414-24.

29. Schiro BDE, Koller HS. Ser adolescente e ser pai/mãe: Gravidez adolescente em uma amostra brasileira. Rev estud Psciolog. 2013; 18(3):447-55.

30. Dias ACG, Teixeira MAP. Gravidez na adolescência: um olhar sobre um fenômeno complexo. Paidéia (Ribeirão Preto). 2010; 20(45):123-31.

Conflito de interesses: Os autores declaram não haver conflito de interesses.

Participação dos autores:

- Concepção: Oliveira PR, Rodrigues JR, Ferreira JD, Batista DJR, Lemes AG. - Desenvolvimento: Oliveira PR, Rodrigues JR, Ferreira JD, Batista DJR, Lemes AG, Gusmão RM, Rocha EM, Franco SEJ.

- Redação e revisão: Oliveira PR, Rodrigues JR, Lemes AG, Rocha EM.

Como citar este artigo: Oliveira PR, Rodrigues JR, Ferreira JD, Batista DJR, Gusmão RM, Franco SEJ, et al. Gravidez na adolescência: um desafio crítico para os países do cone sul. Journal Health NPEPS. 2018 juldez; 3(2):506-526.

Submissão: 02/05/2018

Aceito: $23 / 10 / 2018$

Publicado: $30 / 12 / 2018$ 